\title{
DESIGN AND CHARACTERISATION OF TRANSDERMAL PATCHES OF PHENFORMIN HYDROCHLORIDE
}

\author{
PRATIK SWARUP DAS ${ }^{*}$ PUJA SAHA
}

Pharmacy Institute, Noida Institute of Engineering and Technology

Email: pratikswarupdas@gmail.com

Received: 23 Aug 2017, Revised and Accepted: 13 Oct 2017

\section{ABSTRACT}

Objective: In present work was designed to develop suitable transdermal matrix patches of Phenformin hydrochloride using various hydrophilic (HPMC) and hydrophobic (EUDRAGID) polymers as matrix formers.

Methods: Transdermal patches containing Phenformin hydrochloride were prepared by the solvent casting evaporation technique.

Results: Revealed that prepared patches showed good physical characteristics, no drug-polymer interaction and no skin irritation was observed. The in vitro release study revealed that F3 formulation showed maximum release in 24 h. Formulation F3 was subjected for accelerated stability studies. The F3 formulation was found to be stable as there was no drastic change in the Physico-chemical properties of the patches, which was also confirmed by FTIR.

Conclusion: Thus conclusion can be made that stable transdermal patches of Phenformin hydrochloride have been developed. F1, F2, F3, F4 formulations showed highest cumulative percentage drug release of $98.13 \%, 95.50 \%, 98.65 \%, 97.21 \%$ were obtained during in vitro drug release studies after $24 \mathrm{~h}$. The release of Phenformin hydrochloride appears to be dependent on lipophilicity of the matrix. Moderately lipophillic matrices showed the best release. The predominant release mechanism of the drug through the fabricated matrices was believed to be by a diffusion mechanism. Based upon the in vitro dissolution data the F3 formulation was concluded as optimized formulation.

Keywords: Phenformin hydrochloride, Ethylcellulose, Sodium alginate, Polyethene glycol

(C) 2017 The Authors. Published by Innovare Academic Sciences Pvt Ltd. This is an open access article under the CC BY license (http://creativecommons.org/licenses/by/4.0/] DOI: http://dx.doi.org/10.22159/ijcpr.2017v9i6.23437

\section{INTRODUCTION}

Transdermal drug delivery is one of the most promising methods for drug application. Increasing numbers of drugs are being added to the list of therapeutic agents that can be delivered to the systemic circulation via skin [1-2]. The main advantages of this system are that there is controlled the release of the drug and the medication is painless. The drug is mainly delivered to the skin with the help of a transdermal patch which adheres to the skin [3]. The TDDS has potential advantages of avoiding hepatic first-pass metabolism, maintaining constant blood level for a longer period of time resulting in a reduction of dosing frequency, improved bioavailability, decreased gastrointestinal irritation that occurs due to local contact with gastric mucosa and improved patient compliance [4-5]. Recently it is evident that the benefits of intravenous drug infusion can be duplicated, without its hazards, by using the skin as the port of drug administration to provide continuous transdermal drug infusion into the systemic circulation. Skin consists of membrane barriers, which are mainly composed of lipids and proteins [6-7]. The penetration across epithelial borders is a slow process due to the effect of the barrier properties. The skin, in particular, the stratum corneum, possesses a barrier to drug penetration due to its high density $(1.4 \mathrm{~g} / \mathrm{cm} 2$ in dry state), its low hydration of 15 to $20 \%$. The barrier function is further facilitated by the continuous replacement of stratum corneum, thereby limiting the topical and transdermal bioavailability.

Transdermal drug delivery system attracts many scientists around the world [8]. Transdermal therapeutic systems are designed for controlled drug delivery through the skin into systemic circulation maintaining consistent efficacy and reducing the dose of the drug and its related side effects [9-10]. There are a number of routes by which a molecule can cross the stratum corneum, these are, intercellular, transcellular and appendageal but the intercellular route is considered to be the major pathway for permeation of most drugs across the stratum corneum [11]. The skin as a site of drug delivery has numbers of significant advantages over many other routes of drug administration, including the ability to avoid problems of gastric irritation, $\mathrm{pH}$, and emptying rate effects; avoid hepatic first pass metabolism thereby increasing the bioavailability of drug; reduce the risk of systemic side effects by minimizing plasma concentrations compared to oral therapy; provide a sustained release of drug at the site of application; rapid termination of therapy by removal of the device or formulation, the reduction of fluctuations in plasma levels of drugs and avoids pain associated with injections [12-14].

Phenformin is a biguanide hypoglycemic agent with actions and uses similar to those of Metformin. Although it is generally considered to be associated with an unacceptably high incidence of lactic acidosis, often fatal, it is still available in some countries. Phenformin is an agent belonging to the biguanide class of antidiabetics with antihyperglycemic activity. Phenformin is not used clinically due to the high risk of lactic acidosis that is associated with its use. A biguanide hypoglycemic agent with actions and uses similar to those of metformin. Although it is generally considered to be associated with an unacceptably high incidence of lactic acidosis, often fatal, it is still available in some countries. (From Martindale, The Extra Pharmacopoeia, 30th ed, p290).

\section{MATERIALS AND METHODS}

\section{Materials}

Phenformin hydrochloride was obtained as gift sample from Hetero labs. Pvt india. Eudragit RS100 and Ethyl cellulose were procured from AR chemicals. Other excipients used were of standard pharmaceutical grade and all chemical reagents used were of analytical grade.

\section{Methods}

Preparation of transdermal patch

Transdermal patches containing Phenformin hydrochloride were prepared by the solvent casting evaporation technique. The drug 
Phenformin hydrochloride was dissolved in methanol. Polymers HPMC, Ethylcellulose, Sodium alginate and ERS100 were taken in a boiling tube, to this add Phenformin hydrochloride drug which was previously dissolved in methanol. About $30 \mathrm{ml}$ of a solvent mixture of dichloromethane: methanol (1:1) was added and vortexed. Sufficient care was taken to prevent the formation of lumps. The boiling tube was set aside for $4 \mathrm{~h}$ to allow the polymer to swell. Polyethylene glycol was taken as a plasticizer $(15 \% \mathrm{v} / \mathrm{w}$ of dry polymer weight), and added to the mixture and mixed well. It was set aside for $2 \mathrm{~h}$ to exclude any entrapped air and was then transferred into a previously cleaned Petri plate $\left(40 \mathrm{~cm}^{2}\right)$, drying of patches was carried out in a vacuum oven at room temperature. Dried patches were packed in aluminium foil and stored in a desiccator for further evaluation [15-17].

\section{Evaluation parameters}

\section{Physical appearance [18]}

The prepared patches were found to be uniform, smooth, flexible and homogenous.

Table 1: Formulation design of phenformin hydrochloride transdermal patches

\begin{tabular}{lllllll}
\hline S. No. & Formulation & & \multicolumn{3}{c}{ Ingredients (gms) } \\
\cline { 2 - 5 } & code & Drug (mg) & HPMC & Ethylcellulose & Eudragit \\
\hline 1 & F1 & 100 & 100 & 900 & - & - \\
2 & F2 & 100 & 900 & 100 & - \\
3 & F3 & 100 & - & - & 100 & 900 \\
4 & F4 & 100 & - & - & 900 & 100 \\
\hline
\end{tabular}

\section{Folding endurance [19-20]}

The folding endurance numbers of all the Phenformin hydrochloride patches are 180-292. The folding endurance number gives the mechanical property of the patches, high folding endurance number indicate that has high mechanical property. The folding endurance number was increased with increasing the HPMC content. These results indicated that the patches would not break and maintain their integrity with general skin folding when applied.

\section{Thickness of the film [21]}

Thickness was changed from batch to batch in individual strips of medicated patch carry uniform thickness, which indicates that total medicated patch carry uniform thickness.

\section{Weight uniformity [22]}

The mean weights of all the prepared patches. The weights are in the range of 401.9-539. The formulation patches showed maximum weight which was found within the permissible limits

\section{. Drug content [23]}

The drug content analysis of the prepared formulations has shown that the process employed to prepare the patches was capable of giving uniform drug content with minimum batch variability. All the patches were found to have drug content in the range of $90-101 \%$.
So the method employed i.e. solvent evaporation method is satisfactory for the preparation of Phenformin hydrochloride transdermal patches.

\section{In vitro release study [24-25]}

Phosphate buffer $\mathrm{pH} 7.4$ containing $0.5 \%$ SLS was used as a medium for the release studies and good linearity was observed in the plotted standard graph with a correlation coefficient of 0.999 . The drug release profiles of Phenformin hydrochloride patches containing different ratios of polymers HPMC, Eudragit E100, and Ethylcellulose. It was cleared from the release profiles of formulations, that the drug release was governed by polymer nature and content. The formulations F1, F2, F3, and F4 showed the maximum release when comparing with other formulations due to the high concentration of HPMC polymer. The release was decreased as the concentration of hydrophobic polymer increase.

\section{Stability studies [26]}

Optimized formulations F3 was selected for accelerated stability studies as per ICH guidelines. The patches were observed for colour, appearance and flexibility for a period of three months. The folding endurance, weight, drug content, \% cumulative drug release of the formulation was found to be decreasing. This decrease may be attributed to the harsh environment $\left(40{ }^{\circ} \mathrm{C}\right)$ maintained during the studies.

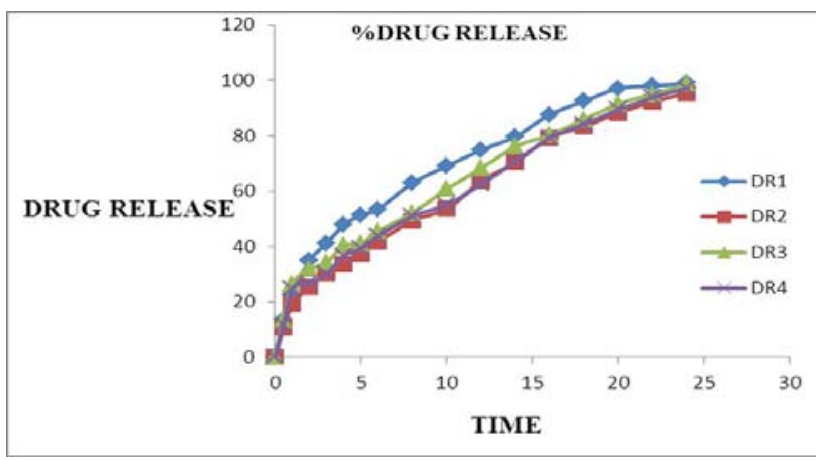

Fig. 1: Drug release formulations

\section{RESULTS}

Table 2: Physicochemical evaluation of phenformin hydrochloride patches

\begin{tabular}{llll}
\hline Formulation code & Weight (mg) & Thickness (mm) & Folding endurance \\
\hline F1 & $473.9 \pm 1.66$ & $0.89 \pm 1.88$ & $292 \pm 4.72$ \\
F2 & $430 \pm 1.58$ & $0.86 \pm 1.72$ & $290 \pm 2.51$ \\
F3 & $486 \pm 0.89$ & $0.81 \pm 1.55$ & $289 \pm 3.46$ \\
F4 & $501.7 \pm 2.50$ & $0.85 \pm 0.99$ & $291 \pm 3.18$ \\
\hline
\end{tabular}


Table 3: In vitro drug release profiles of phenformin hydrochloride transdermal patch (F1-F4)

\begin{tabular}{llll}
\hline Time (h) & \multicolumn{3}{l}{ \% Cumulative drug released } \\
\cline { 2 - 4 } & F1 & F2 & F3 \\
\hline 0 & 0 & 0 & 0 \\
0.5 & $13.56 \pm 1.43$ & $10.65 \pm 1.44$ & $13.48 \pm 1.27$ \\
1 & $22.72 \pm 1.87$ & $19.27 \pm 1.49$ & $26.50 \pm 1.33$ \\
2 & $34.94 \pm 1.26$ & $25.49 \pm 1.77$ & $31.71 \pm 1.45$ \\
3 & $41.16 \pm 1.33$ & $30.28 \pm 1.29$ & $34.36 \pm 1.72$ \\
4 & $47.88 \pm 1.89$ & $33.63 \pm 1.39$ & $40.25 \pm 1.63$ \\
5 & $51.33 \pm 2.0$ & $37.46 \pm 2.1$ & $41.07 \pm 1.82$ \\
6 & $53.46 \pm 2.3$ & $41.60 \pm 1.27$ & $45.53 \pm 1.25$ \\
8 & $62.87 \pm 1.67$ & $49.35 \pm 1.71$ & $52.15 \pm 1.19$ \\
10 & $69.01 \pm 1.31$ & $53.61 \pm 1.33$ & $60.71 \pm 1.32$ \\
12 & $74.93 \pm 1.56$ & $63.49 \pm 1.92$ & $68.30 \pm 1.83$ \\
14 & $79.70 \pm 1.19$ & $70.45 \pm 1.68$ & $76.11 \pm 1.95$ \\
16 & $87.64 \pm 1.88$ & $79.33 \pm 1.18$ & $80.27 \pm 1.18$ \\
18 & $92.49 \pm 1.3$ & $83.80 \pm 1.22$ & $85.93 \pm 2.5$ \\
20 & $97.08 \pm 1.99$ & $88.34 \pm 1.82$ & $91.44 \pm 2.41$ \\
22 & $98.01 \pm 1.25$ & $92.20 \pm 2.39$ & $95.09 \pm 1.85$ \\
\end{tabular}

Table 4: Stability studies of optimized formulations at $40 \pm 2{ }^{\circ} \mathrm{C}$ and $75 \pm 5 \% \mathrm{RH}$ for $3 \mathrm{mo}$

\begin{tabular}{lllll}
\hline Time in d & Drug content (\%) & Folding endurance & Physical appearance & \% cumulative drug release \\
\hline 0 & 98 & 285 & No change in color & 97 \\
90 & 97.1 & 281 & Slight yellowish color & 96.35 \\
\hline
\end{tabular}

\section{Stability studies}

Optimized formulations F3 was selected for accelerated stability studies as per ICH guidelines.

\section{CONCLUSION}

Results revealed that prepared patches showed good physical characteristics, no drug-polymer interaction and no skin irritation was observed. The F3 formulation was found to be stable as there was no drastic change in the Physico-chemical properties of the patches, which was also confirmed by FTIR. This conclusion can be made that stable transdermal patches of Phenformin hydrochloride have been developed. F1, F2, F3, F4 formulations showed highest cumulative percentage drug release of $98.65 \%, 95.50 \%, 98.93 \%, 97.21 \%$ were obtained during in vitro drug release studies after $24 \mathrm{~h}$. The release of Phenformin hydrochloride appears to be dependent on lipophilicity of the matrix. Moderately lipophilic matrices showed the best release. The predominant release mechanism of the drug through the fabricated matrices was believed to be by a diffusion mechanism. Based upon the in vitro dissolution data the F3 formulation was concluded as optimized formulation.

\section{CONFLICT OF INTERESTS}

Declared none

\section{REFERENCES}

1. Cross SE, Robert MS. Targeting local tissues by transdermal application: understanding drug physicochemical properties. Drug Development Res 1999;46:309-15.

2. Finnin BC. Transdermal drug delivery-what to expect in the near future. Business Briefing Pharmatech; 2003. p. 192-3.

3. Ghosh TK, Pfister WR. Transdermal and topical drug delivery systems. Int. Pharm, Press; 2012. p. 39.

4. Hadgraft J, Guy R. In: Transdermal Drug Delivery. Marcel Dekker, Inc., New York and Basel; 1991. p. 296.

5. Chein YW. Transdermal drug delivery and delivery system. In: Novel drug delivery system. Vol. 50. Marcel Dekker, Inc., New York; 1992. p. 301-81.

6. Martin A, Swabrik J, Cammarara A. Physical pharmacy. $4^{\text {th }}$ ed. New delhi: B. I Vaverly Pvt Ltd; 1996. p. 264-8.

7. RL Cleek, AL Bunge. A new method for estimating dermal absorption from chemical exposure. General approach Pharm Res 1993;10:497-506.
8. Ghosh TK, Jasti BR. editors. Theory and Practice of Contemporary Pharmaceutics. ${ }^{\text {st }}$ ed. Florida: CRC Press; 2005. p. 423-53.

9. Roberts MS. Targeted drug delivery to the skin and deeper tissues: role of physiology, solute structure and disease. Clin Exp Pharmacol Physiol 1997;24:874-9.

10. Berner B, John VA. Pharmacokinetic characterization of transdermal delivery systems. Clin Pharmacokinetics 1994;26:121-34.

11. Schaefer H. Penetration, permeation, and absorption of triamcinolone acetonide in the normal and psoriatic skin. Arch Dermatol 1977;258:241-9.

12. Ghosh TK. Development of a transdermal patch of methadone: in vitro evaluation across hairless mouse and human cadaver skin. Pharm Dev Technol 1996;1:285-91.

13. Gaur KP, Mishra S, Purohit S, Dave K. Transdermal delivery system: a review. Asian J Pharm Clin Res 2009;2:14-20.

14. Kumar Ritesh, Philip Anil. Modified transdermal technologies: Breaking the barriers of drug permeation via the skin. Trop J Pharm Res 2007;6:633-44.

15. Singh PB, Choudhury PK. Penetration enhancers for transdermal drug delivery of systemic agents. J Pharm Res 2007;6:44-50.

16. Guyot M, Fawas F. Design and in vitro evaluation of adhesive matrix for transdermal delivery of propranolol. Int J Pharm 2000;204:171-82.

17. Rao PR, Reddy MN, Ramakrishna S, Diwan PV. Comparative in vivo evaluation of propranolol hydrochloride after oral and transdermal administration in rabbits. Eur J Pharm Biopharm 2003;56:81-5.

18. Manvi FV, Dandagi PM, Gadad AP, Mastiholimath VS. Formulation of a transdermal drug delivery system of ketotifen fumarate. Indian J Pharm Sci 2003;65:239-43.

19. Gupta SP, Jain SK. Effective and controlled transdermal delivery of metoprolol tartarate. Indian J Pharm Sci 2005;67:346-50.

20. Bharkatiya M, Nema RK, Gupta GD, Gaud RS. Designing and evaluation of propranolol hydrochloride transderma patches. Pharma Rev 2005;204:113-6.

21. Das MK, Bhattacharya A, Ghosal SK. Transderma drug delivery of trazodone hydrochloride form acrylic film prepared from aqueous latex. Indian J Pharm Sci 2006;68:41-6.

22. Soni Mohit, Kumar Sandeep, Gupta DR. GD: Transdermal drug delivery: a novel approach to skin permeation. J Pharm Res 2009;2:1184-90. 
23. Naik Aarti, Yogeshvar N, Kalia Guy, Richard Guy H. Transdermal drug delivery: overcoming the skin's barrier function. Pharm Sci Technol Today 2009;3:318-26.

24. Arunachalam A, Karthikeyan, Vinay Kumar D, Prathap M, Sethuraman S, Ashutosh Kumar S, Manidipa S. Transdermal drug delivery system: a review. Curr Pharma Res 2010;1:70-81.

25. Loyd V, Allen Jr, Nicholas G Popovich, Howard C Ansel. Pharmaceutical dosage forms and drug delivery systems. 8th Edition. Wolter Kluwer Publishers, New Delhi; 2005. p. 298-9.
26. Mukherjee B, Mahapatra S, Gupta R, Patra B, Tiwari A, Arora $P$. A comparison between povidone ethylcellulose and povidone-eudragit transdermal dexamethasone matrix patches based on in vitro skin permeation. Eur J Pharm Biopharm 2005;59:475-83.

27. Arora P, Mukherjee B. Design, development, physicochemical, and in vitro and in vivo evaluation of transdermal patches containing diclofenac diethylammonium salt. J Pharm Sci 2002;91:2076-89. 